\title{
Simultaneous exposure to estrogen and androgen resulted in feminization and endocrine disruption
}

\author{
Lili Chen, Xiaolong Jiang, Haiwei Feng, Hongjuan Shi, Lina Sun, Wenjing Tao, \\ Qingping Xie and Deshou Wang
}

Key Laboratory of Freshwater Fish Reproduction and Development (Ministry of Education), Key Laboratory of Aquatic Science of Chongqing, School of Life Sciences, Southwest University, Chongqing 400715, China
Correspondence should be addressed to D Wang Email wdeshou@swu.edu.cn

\begin{abstract}
Estrogen, which is synthesized earlier in females than androgen in males, is critical for sex determination in non-mammalian vertebrates. However, it remains unknown that what would happen to the gonadal phenotype if estrogen and androgen were administrated simultaneously. In this study, XY and XX tilapia fry were treated with the same dose of $17 \alpha$-methyltestosterone $(\mathrm{MT})$ and $17 \beta$-estradiol $\left(\mathrm{E}_{2}\right)$ alone and in combination from 0 to 30 days after hatching. Treatment of $X Y$ fish with $E_{2}$ resulted in male to female sex reversal, while treatment of $X X$ fish with MT resulted in female to male sex reversal. In contrast, simultaneous treatment of $X X$ and $X Y$ fish with $M T$ and $E_{2}$ resulted in female, but with cyp11b2 and cyp19a1a co-expressed in the ovary. Serum 11-ketotestosteron level of the MT and $E_{2}$ simultaneously treated $X X$ and $X Y$ female was similar to that of the $X Y$ control, while serum $E_{2}$ level of these two groups was similar to that of the $X X$ control. Transcriptomic cluster analysis revealed that the $M T$ and $E_{2}$ treated $X X$ and $X Y$ gonads clustered into the same branch with the $\mathrm{XX}$ control. However a small fraction of genes, which showed disordered expression, may be associated with stress response. These results demonstrated that estrogen could maintain the female phenotype of $X X$ fish and feminize $X Y$ fish even in the presence of androgen. Simultaneous treatment with estrogen and androgen up-regulated the endogenous estrogen and androgen synthesis, and resulted in disordered gene expression and endocrine disruption in tilapia.
\end{abstract}

Key Words

- 17 $\alpha$-methyl testosterone

- 17 $\beta$-estradiol

- simultaneous administration

- disordered gene expression

\section{Introduction}

In vertebrates, sex is determined either genetically (genetic sex determination, GSD) or environmentally (environmental sex determination, ESD), or a combination of both. In mammal, sex is completely determined by GSD. In contrast, in non-eutherian vertebrates, environmental factors, especially steroid hormones, play a critical role in the sex determination.
In teleost, endogenous estrogens act as the natural inducer of ovarian differentiation, while androgen is not synthesized in the gonad during the critical period of sex determination (Nagahama 2000). In tilapia, several essential steroidogenic enzymes, Cyp11a1, 3 $\beta$-HSD, Cyp $17 \alpha 1$ and Cyp19a1a, were detected in the gonads of XX fry at 10 days after hatching (dah) by immunohistochemistry

Published by Bioscientifica Ltd 


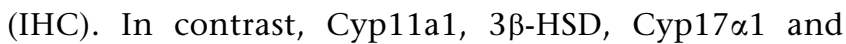
Cyp11b2 were not observed in the testis of XY fish until 30 dah (Kobayashi et al. 1996, Morrey et al. 1998). In a recent study of gonadal transcriptomes from the Nile tilapia, we further confirmed that almost all steroidogenic enzyme genes, including cyp19a1a but not including cyp11b2, were up-regulated in the XX gonads at 5 dah, while these enzyme genes, including cyp11b2 but not including cyp19a1a, were detected at 30 dah and significantly up-regulated from 90 dah onwards in the XY gonads (Takatsu et al. 2013). The pivotal role of estrogens in sex determination and differentiation has been demonstrated in various teleosts (Piferrer et al. 1994, D'Cotta et al. 2001, Kobayashi et al. 2003, Vizziano et al. 2008) and other non-eutherian vertebrates (Wibbels \& Crews 1994, Merchant-Larios et al. 1997, Hudson et al. 2005).

Endocrine disruptor chemicals are referred to those exogenous substances that can interfere with the endocrine system and then lead to a range of developmental, reproductive, immune, neurological or metabolic diseases in human and animals (Diamanti-Kandarakis et al. 2009). Up to now, steroid hormones have been widely used for sex control in fish for higher commercial value in aquaculture. Environmental sex steroid can mimic the natural sex steroid and disrupt the endocrine system of aquatic animals, which results in disorders and epigenetic modification in sex determination and differentiation. Endogenous hormones such as estrogens and androgens could activate nuclear receptors and then regulate the expression of a large number of genes which would have profound effects on the organisms (Li et al. 2015a,b).

Epigenetic mechanisms provide organisms with the ability to modify the activity of their genes in response to changes in the internal or external environment (Piferrer 2013). Genes in the sex determination pathways are the major targets of substantial methylation modification (Navarro-Martin et al. 2011, Zhang et al. 2013, Parrott et al. 2014, Shao et al. 2014). The different expression patterns of DNA methyltransferases (DNMTs) in gonads are probably essential for the acquisition of a sex-specific methylation pattern (La Salle et al. 2004).

Actually, fishes and other vertebrates live in an environment with both androgenic and estrogenic substances, and therefore, it would be interesting to know i) what would happen to the gonadal phenotype if XX and $\mathrm{XY}$ fish were exposed simultaneously to estrogen and androgen during the critical period of sex differentiation? ii) Is their sex still controlled by the genetic sex or otherwise by estrogen irrespective to their genetic sex? iii) Is the gonadal gene expression profile of the treated fish testis-like, ovary-like or disrupted? iv) Is epigenetic modification (methyltransferase dnmt genes expression) involved in the process? To answer these questions, we treated all-XX and all-XY tilapia fry with $17 \beta$-estradiol $\left(\mathrm{E}_{2}\right)$ and $17 \alpha$-methyltestosterone (MT) alone or simultaneously from 0 to $30 \mathrm{dah}$, and analyzed the gonadal phenotype and gene expression profile. Our results indicated that MT and $E_{2}$ treated fish developed into females irrespective of their genetic sex. The global gene expression profiles of the gonads were in conformity with their phenotype, while a small fraction of genes showed disordered expression profiles.

\section{Materials and methods}

\section{Animals}

The Nile tilapia (Oreochromis niloticus) was reared in recirculating aerated freshwater tanks at $26{ }^{\circ} \mathrm{C}$ under a natural photoperiod. All-XX progenies were obtained by crossing a XX pseudomale with a normal XX female. All-XY progenies were obtained by crossing a YY supermale with a normal female. Animal experiments were conducted in accordance with the regulations of the Guide for Care and Use of Laboratory Animals and were approved by the Committee of Laboratory Animal Experimentation at Southwest University.

\section{Hormone treatment}

$\mathrm{XX}$ fry were divided into MT and $\mathrm{E}_{2}$ treatment $\left(\mathrm{MT}+\mathrm{E}_{2}-\right.$ $\mathrm{XX}$ ), MT treatment (MT-XX) and XX control (Ctrl-XX) groups. While $\mathrm{XY}$ fry were divided into $\mathrm{MT}$ and $\mathrm{E}_{2}$ treatment $\left(\mathrm{MT}+\mathrm{E}_{2}-\mathrm{XY}\right), \mathrm{E}_{2}$ treatment $\left(\mathrm{E}_{2}-\mathrm{XY}\right)$ and control (Ctrl-XY) groups. The control fish were raised in steroidfree water and fed with normal commercial diet. In treatment group, the newly hatched $\mathrm{XX}$ and $\mathrm{XY}$ fry were first exposed to water containing $50 \mu \mathrm{g} / \mathrm{l}$ of MT and $\mathrm{E}_{2}$ (Sigma-Aldrich) alone or in combination from 0 to 5 dah, and then fed with commercial diet sprayed with $95 \%$ ethanol containing the same dose $(50 \mu \mathrm{g} / \mathrm{g}$ feed) of MT and $\mathrm{E}_{2}$ alone or in combination until $30 \mathrm{dah}$. Later on, all fish were raised in steroid-free water and fed with normal commercial diet. The treatments were repeated three times.

Gonads were sampled at 5, 10, 30 and 90 dah and fixed in Bouin's solution for subsequent histological observations and IHC analyses. Gonads were also sampled at 90 dah for real-time PCR and transcriptome analyses. Six fish from the Ctrl-XX, MT-XX, MT $+\mathrm{E}_{2}-\mathrm{XX}$, Ctrl-XY,

Published by Bioscientifica Ltd. 
sex reversed $\mathrm{E}_{2}-\mathrm{XY}$ and sex reversed $\mathrm{MT}+\mathrm{E}_{2}-\mathrm{XY}$ fish were sampled for real-time PCR. The gonad phenotype was determined by histological examination. The sex reversal rate and survival rate were calculated at 90 dah.

\section{IHC and western blot}

Gonads were dissected, fixed in Bouin's solution for $12 \mathrm{~h}$ at room temperature and embedded in paraffin. All tissue blocks were sectioned at $5 \mu \mathrm{m}$ for IHC analyses. Antibodies against Cyp19a1a, the key enzyme for $\mathrm{E}_{2}$ synthesis, and Cyp11b2, the key enzyme for 11-ketotestosteron (11-KT) synthesis, were produced by our laboratory, and were diluted by $1: 1000$ and 1:500 respectively in use. IHC analyses were performed as described previously (Sun et al. 2014). Photographs were taken under light microscope (Olympus BX 51). Total protein was extracted from Ctrl-XX, MT $+\mathrm{E}_{2}-\mathrm{XX}, \mathrm{MT}+\mathrm{E}_{2}-\mathrm{XY}$ and Ctrl-XY gonads of 90 dah tilapia and western blot analyses were performed as reported previously (Li et al. 2012).

\section{Measurement of serum 11-KT and $E_{2}$ levels by EIA}

Blood samples were collected from the caudal veins of the treatment and control fish at 90 dah, and then, kept at $4{ }^{\circ} \mathrm{C}$ overnight. Serums were collected after centrifugation and stored at $-20^{\circ} \mathrm{C}$ until use. Serum 11-KT and $\mathrm{E}_{2}$ levels were measured using the enzyme immunoassay (EIA) kit (Cayman Chemical Co., Ann Arbor, MI, USA) following the manufacturer's instructions.

\section{Transcriptome analysis}

The Ctrl-XX and Ctrl-XY gonad transcriptomes were sequenced previously by our group (Tao et al. 2013). One ovary from each of the $\mathrm{MT}+\mathrm{E}_{2}-\mathrm{XX}$ fish and the sex reversed $\mathrm{MT}+\mathrm{E}_{2}-\mathrm{XY}$ fish was used for transcriptome analyses. Total RNAs were extracted from ovaries using RNeasy Mini Kit (50) (Qiagen) according to the manufacturer's instructions. The extracted RNAs were further treated with deoxyribonuclease 1 (ribonuclease free) to eliminate genomic DNA contamination. The oligo (dT) beads enriched mRNA was disrupted into short fragments (200-700 nt) using fragmentation buffer. These short fragments were used as templates for first- and secondstrand cDNA synthesis using a DNA synthesis kit (Invitrogen). A QiaQuick PCR purification kit (Qiagen) was used to purify these fragments, and the elution buffer was used for end repair and addition of the poly (A) tail. Then, these short fragments were ligated with sequencing adapters. After agarose gel electrophoresis, fragments between 320 and $370 \mathrm{nt}$ were cut from the gel for PCR amplification. Two cDNA libraries were constructed from the two samples and sequenced on an Illumina HiSeq 2000 instrument. Clean reads with a quality score $\geq$ Q20 from each library were aligned to the reference genome (Orenil1.0, http://www.ensembl.org/Oreochromis_niloticus/Info/Index) using Tophat with default parameters, and the reads per $\mathrm{kb}$ per million reads (RPKM) method was used to calculated gene expression level (Mortazavi et al. 2008). The assembled transcripts were merged with the reference annotation (Oreochromis_niloticus.Orenill. 0.78.gtf, downloaded from Ensembl) using cuffmerge, and differential expression analysis was performed using cuffdiff.

Four transcriptomes of Ctrl-XX, Ctrl-XY, MT $+\mathrm{E}_{2}-\mathrm{XX}$ and $\mathrm{MT}+\mathrm{E}_{2}-\mathrm{XY}$ were used to analyze the genes expression profiles. The threshold for the $P$ value was determined using false discovery rate (FDR), and was widely set at $10^{-2}$ (Tao et al. 2013). In this study, genes with RPKM $<1$ in the transcriptome were considered as background expression. They were excluded from analysis. Gonadal expressed genes were divided into non-differentially expressed genes between Ctrl-XX and Ctrl-XY (F/M-NDGs), Ctrl-XX up-regulated genes (F-UPGs) and Ctrl-XY (M-UPGs) up-regulated genes. (M-UPGs) 'FDR $>10^{-2,}$ and ' $-1<\log 2$ (Ctrl-XX_RPKM/Ctrl-XY_RPKM) $<1$ ' were used to identify F/M-NDGs, 'FDR $\leq 10^{-2,}$ and $\mid \log 2$ (Ctrl-XX_RPKM/CtrlXY_RPKM) $\mid \geq 1$ were used to identify F-UPGs and M-UPGs. These standards were also used for identification of nondifferentially expressed, up- and down-regulated genes in $\mathrm{MT}+\mathrm{E}_{2}-\mathrm{XX}$ and $\mathrm{MT}+\mathrm{E}_{2}-\mathrm{XY}$. Cluster analyses of gene expression patterns were performed with cluster and Java Treeview Software (http://jtreeview.sourceforge.net/; http://rana.lbl.gov/EisenSoftware.htm) (Eisen et al. 1998).

\section{Real-time PCR analysis}

Real-time PCR was carried out on an ABI-7500 real-time PCR machine according to the protocol of SYBR Premix Ex Taq II (Takara, Tokyo, Japan) using $\beta$-actin, gapdh and eEF1A1a as internal control. Gonads from Ctrl-XX, MT$\mathrm{XX}, \mathrm{MT}+\mathrm{E}_{2}-\mathrm{XX}, \mathrm{Ctrl}-\mathrm{XY}, \mathrm{E}_{2}-\mathrm{XY}$ and $\mathrm{MT}+\mathrm{E}_{2}-\mathrm{XY}$ fish were analyzed. Six samples were used for each group. Total RNAs were extracted from each sample and reverse transcribed using PrimeScript RT Master Mix Perfect Real Time Kit (Takara, Tokyo, Japan) according to the manufacturer's instructions. igf3, cyp19a1b, wt1b, dnmt1, dnmt3 and $d n m t 7$ were selected to validate the transcriptome data by real-time PCR using gene-specific primers (Table S1, see

Published by Bioscientifica Ltd. 
section on supplementary data given at the end of this article). The relative abundance of mRNA transcripts was evaluated using the formula: $R=2^{-\Delta \Delta \mathrm{Ct}}$, as described previously (Tao et al. 2013).

\section{Results}

\section{$M T$ and $E_{2}$ treatment on gonad phenotype}

The $\mathrm{XX}$ and $\mathrm{XY}$ fry were treated by $\mathrm{MT}$ and $\mathrm{E}_{2}$ alone or simultaneously from 0 to $30 \mathrm{dah}$. The gonad phenotypes were determined histologically at 90 dah. All Ctrl-XX and $\mathrm{MT}+\mathrm{E}_{2}$-XX fish developed as female with normal ovary. All MT-XX fish displayed female to male sex reversal with typical testis. These sex reversed fish were fertile as they produced normal sperms which could fertilize the eggs to produce viable offspring. In contrast, all Ctrl-XY fish developed as male with normal testis, while $63 \% \mathrm{E}_{2}-\mathrm{XY}$ fish and $52 \% \mathrm{MT}+\mathrm{E}_{2}-\mathrm{XY}$ fish displayed male to female sex reversal with typical ovaries. These sex reversed fish were fertile as they produced normal eggs which could be fertilized by the sperms to produce viable offspring. Survival and sex reversal rates of the control and treatment groups were shown in Table 1.

\section{MT and $E_{2}$ treatment on gonadal cyp19ala, dmrt1 and cyp11b2 expression}

IHC analyses were performed for cyp19ala, dmrt1 and cyp11b2 (Fig. 1). cyp19a1a was found to be expressed in the gonad of the Ctrl-XX and MT $+\mathrm{E}_{2}-\mathrm{XX}$ at 5, 10 and 30 dah, in the gonad of the MT-XX at 5 and 10 dah and in the gonad of both $\mathrm{MT}+\mathrm{E}_{2}-\mathrm{XY}$ and $\mathrm{E}_{2}-\mathrm{XY}$ at 10 and 30 dah. dmrt1 was expressed in the gonad of MT-XX at 10 and 30 dah, in the gonad of both $\mathrm{MT}+\mathrm{E}_{2}-\mathrm{XY}$ and $\mathrm{E}_{2}-\mathrm{XY}$ at 5 and $10 \mathrm{dah}$ and in the gonad of Ctrl-XY at 5, 10 and 30 dah. cyp11b2 was expressed in the gonad of the MT-XX, $\mathrm{MT}+\mathrm{E}_{2}-\mathrm{XX}, \mathrm{MT}+\mathrm{E}_{2}-\mathrm{XY}$ and Ctrl-XY at $30 \mathrm{dah}$. At 90 dah, Cyp19a1a was expressed in the interstitial cells of the
Ctrl-XX and $\mathrm{E}_{2}-\mathrm{XY}$ ovaries, while cyp11b2 was expressed in the Leydig cells of the MT-XX and Ctrl-XY testes. However, cyp19a1a and cyp11b2 were co-expressed in the interstitial cells of the sex reversed ovaries of $\mathrm{MT}+\mathrm{E}_{2}-\mathrm{XX}$ and $\mathrm{MT}+$ $\mathrm{E}_{2}$-XY at 90 dah (Fig. 1). Like Ctrl-XY, only Cyp11b2 was detected in the Leydig cells of the testis of the MT $+\mathrm{E}_{2}-\mathrm{XY}$ and $\mathrm{E}_{2}-\mathrm{XY}$ fish which experienced no sex reversal (Fig. S1, see section on supplementary data given at the end of this article). Consistently, by western blotting strong band of Cyp19a1a was detected in the ovaries of the Ctrl-XX fish, and strong band of Cyp11b2 was detected in the testes of the Ctrl-XY fish, while strong band of Cyp19a1a and weak band of Cyp11b2 were detected in the ovaries of both $\mathrm{MT}+\mathrm{E}_{2}-\mathrm{XX}$ and $\mathrm{MT}+\mathrm{E}_{2}-\mathrm{XY}$ fish (Fig. 2).

\section{MT and $E_{2}$ treatment on serum 11-KT and $E_{2}$ levels}

At 90 dah, the serum $\mathrm{E}_{2}$ and 11-KT levels of the MT-XX were similar to those of the Ctrl-XY. Serum $E_{2}$ level of $\mathrm{E}_{2}-\mathrm{XY}$ was significant lower than while serum 11-KT level similar to that of the Ctrl-XX. Interestingly, serum $\mathrm{E}_{2}$ level of both $\mathrm{MT}+\mathrm{E}_{2}-\mathrm{XX}$ and $\mathrm{MT}+\mathrm{E}_{2}-\mathrm{XY}$ showed no significant difference with that of the Ctrl-XX. Serum 11-KT level of both $\mathrm{MT}+\mathrm{E}_{2}-\mathrm{XX}$ and $\mathrm{MT}+\mathrm{E}_{2}-\mathrm{XY}$ was similar to that of the Ctrl-XY (Fig. 3A and B).

\section{MT and $E_{2}$ treatment on gonad global gene expression}

Sequencing of gonadal transcriptomes from $\mathrm{MT}+\mathrm{E}_{2}-\mathrm{XX}$ and $\mathrm{MT}+\mathrm{E}_{2}-\mathrm{XY}$ yielded a total of 123897206 and 118566266 reads respectively. The total gene counts of both MT $+\mathrm{E}_{2}-\mathrm{XX}$ (19979) and MT $+\mathrm{E}_{2}-\mathrm{XY}$ (19034) were larger than that of Ctrl-XX (18100), but the total gene counts of MT $+\mathrm{E}_{2}-\mathrm{XY}$ was less than that of Ctrl-XY (19790) (Fig. 4A).

Cluster analysis of gene expression patterns of gonadal transcriptomes from $\mathrm{MT}+\mathrm{E}_{2}-\mathrm{XX}, \mathrm{MT}+\mathrm{E}_{2}-\mathrm{XY}, \mathrm{Ctrl}-\mathrm{XX}$ and Ctrl-XY at 90 dah was performed. The resulting

Table 1 Survival and sex reversal rate after MT and $E_{2}$ treatment in tilapia

\begin{tabular}{|c|c|c|c|c|c|}
\hline Genetic sex & Treatment & $\begin{array}{c}\text { Fish number } \\
\text { treatment }\end{array}$ & $\begin{array}{c}\text { Fish number after } \\
\text { treatment }\end{array}$ & $\begin{array}{l}\text { Survival } \\
\text { rate }(\%)\end{array}$ & $\begin{array}{c}\text { Sex reversal } \\
\text { rate }(\%)\end{array}$ \\
\hline \multirow[t]{3}{*}{$X X$} & Ctrl-XX & 120 & 114 & 95 & 0 \\
\hline & MT-XX & 120 & 90 & 75 & 100 \\
\hline & $M T+E_{2}-X X$ & 120 & 75 & 63 & 0 \\
\hline \multirow[t]{3}{*}{$X Y$} & Ctrl-XY & 120 & 117 & 98 & 0 \\
\hline & $E_{2}-X Y$ & 120 & 106 & 88 & 63 \\
\hline & $M T+E_{2}-X Y$ & 120 & 64 & 54 & 52 \\
\hline
\end{tabular}

The fish were treated with $\mathrm{E}_{2}$ and MT along or in combination, $50 \mu \mathrm{g} / \mathrm{l}$ water bath from 0 to 5 dah and then fed with $50 \mu \mathrm{g} / \mathrm{g}$ diet to 30 dah. Survival rate and sex reversal rate were examined and calculated at 90 dah.

http://joe.endocrinology-journals.org DOI: $10.1530 / \mathrm{JOE}-15-0432$
(C) 2016 Society for Endocrinology Printed in Great Britain
Published by Bioscientifica Ltd 

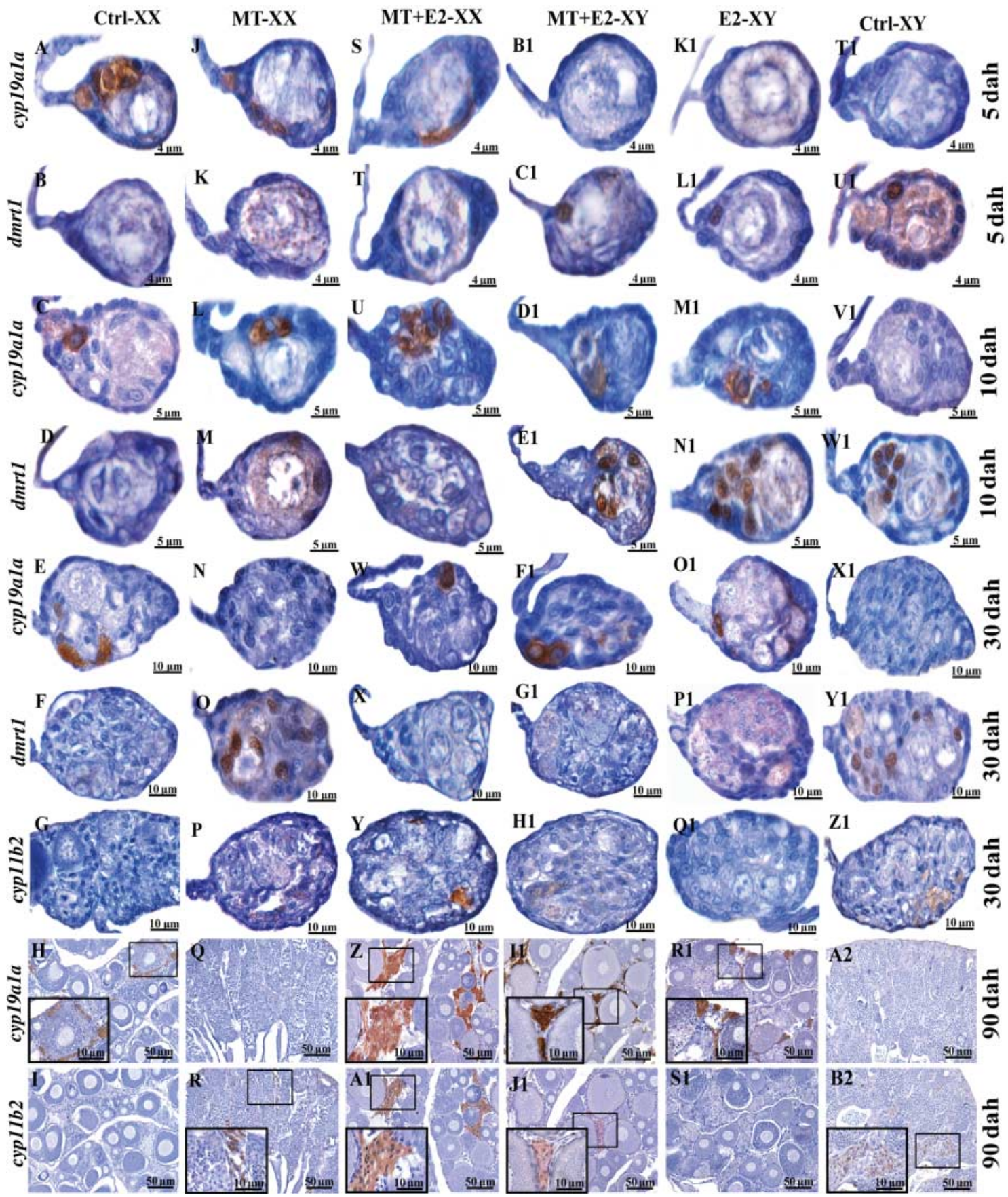

\section{Figure 1}

cyp19a1a, dmrt1 and cyp11b2 expression in gonads of Ctrl-XX (A-I), MT-XX (J-R), MT+ $E_{2}-X X(S-A 1), M T+E_{2}-X Y$ (B1-J1), $E_{2}-X Y(K 1-S 1)$ and Ctrl-XY (T1-B2) fish from 5 to 90 dah by immunohistochemistry. $X Y$ and $X X$ fish were treated by $17 \beta$-estradiol $\left(E_{2}\right)$ and $17 \alpha$-methyltestosterone (MT) respectively for 30 days by exposed to $50 \mu \mathrm{g} / \mathrm{l}$ of $\mathrm{MT}$ and $\mathrm{E}_{2}$ alone and in combination from 0 to 5 dah, fed with commercial diet with $50 \mu \mathrm{g} / \mathrm{g}$ feed of $\mathrm{MT}$ and $\mathrm{E}_{2}$ alone or in combination until 30 dah, and then fed with control diet to $90 \mathrm{dah}$. The control fish were raised in steroid-free water and fed with normal commercial diet. The treatment was repeated three times. cyp 19a 1a was expressed in the gonad of the $\mathrm{Ctrl}-\mathrm{XX}$ and $\mathrm{MT}+\mathrm{E}_{2}-\mathrm{XX}$ at 5,10 and 30 dah $(A, C, E$ and $S, U, W)$, in the gonad of the MT-XX at 5 and 10 dah Printed in Great Britain
( $\mathrm{J}$ and $\mathrm{L}$ ) and in the gonad of both $\mathrm{MT}+\mathrm{E}_{2}-\mathrm{XY}$ and $\mathrm{E}_{2}-\mathrm{XY}$ at 10 and 30 dah (D1, F1 and M1, Q1). dmrt1 was expressed in the gonad of MT-XX at 10 and 30 dah ( $\mathrm{M}$ and $\mathrm{O}$ ), in the gonad of both $\mathrm{MT}+\mathrm{E}_{2}-\mathrm{XY}$ and $\mathrm{E}_{2}-\mathrm{XY}$ at 5 and 10 dah $(C 1, E 1$ and $L 1, N 1)$ and in the gonad of Ctrl-XY at 5, 10 and 30 dah (U1, W1 and $\mathrm{Y} 1$ ). cyp11b2 was expressed in the gonad of Ctrl-XY (Z1) and in $\mathrm{MT}-\mathrm{XX}, \mathrm{MT}+\mathrm{E}_{2}-\mathrm{XX}$ and $\mathrm{MT}+\mathrm{E}_{2}-\mathrm{XY}$ at 30 dah (P, Y, H1). cyp19a1a was expressed in the Ctrl-XX ovary at 90 dah $(\mathrm{H})$, while cyp11b2 was expressed in the Leydig cells of the Ctrl-XY (B2). However, cyp19a1a and cyp11b2 were co-expressed in the interstitial cells of the $M T+E_{2}-X X$ and $M T+E_{2}-X Y\left(Z_{1} A 1\right.$ and I1, J1) ovaries. dah, day after hatching. The positive signal corresponds to the brownish color.

Published by Bioscientifica Ltd. 


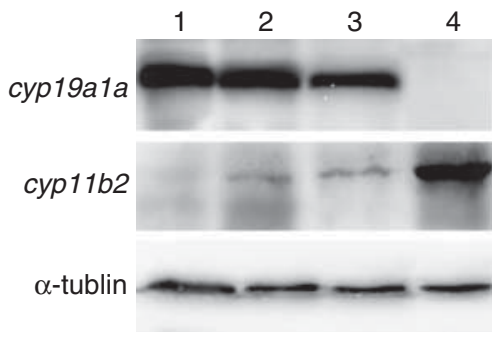

\section{Figure 2}

Expression of cyp11b2 and cyp19a1a in tilapia gonads at 90 dah by western blotting. Lanes 1-4, proteins extracted from the gonads of Ctrl-XX, MT+ $E_{2^{-}}$ $\mathrm{XX}, \mathrm{MT}+\mathrm{E}_{2}-\mathrm{XY}$ and Ctrl-XY fish at 90 dah respectively. Cyp19a1a was detected in the gonads of Ctrl-XX, MT $+E_{2}-X X$ and $M T+E_{2}-X Y$ fish, while Cyp11b2 was detected in the gonads of MT $+E_{2}-X X, M T+E_{2}-X Y$ and Ctrl-XY fish. $\alpha$-tubulin was used to validate equal loading for western blot analysis and as reference protein for densitometry analysis.

dendrogram contained two main branches (I and II). Gonadal transcriptome from Ctrl-XY group clustered into branch II and those from the other three groups, which displayed extremely similar expression profile, clustered into branch I (Fig. 4B).

Of the gonadal expressed genes, 5170 genes were F-UPGs, account for 33\%; 5662 genes were F/M-NDGs, account for 36\%; 4864 genes were M-UPGs, account for $31 \%$. Of the F-UPGs $14 \%$ in $\mathrm{MT}+\mathrm{E}_{2}-\mathrm{XX}, 13 \%$ in $\mathrm{MT}+\mathrm{E}_{2}-$ $\mathrm{XY}$ and $8 \%$ in both were up-regulated; $56 \%$ in $\mathrm{MT}+\mathrm{E}_{2}-\mathrm{XX}$, $77 \%$ in $\mathrm{MT}+\mathrm{E}_{2}-\mathrm{XY}$ and $49 \%$ in both displayed no change, which were consistent with the ovarian phenotype; however, $30 \%$ in $\mathrm{MT}+\mathrm{E}_{2}-\mathrm{XX}, 10 \%$ in $\mathrm{MT}+\mathrm{E}_{2}-\mathrm{XY}$ (of which 159 genes, $3 \%$, represented with shadow, were upregulated compared with $\mathrm{Ctrl}-\mathrm{XY}$ ) and $7 \%$ in both were down-regulated compared with Ctrl-XX, which were inconsistent with the ovarian phenotype (Fig. 4C). Of the $\mathrm{F} / \mathrm{M}-\mathrm{NDGs} 17 \%$ in $\mathrm{MT}+\mathrm{E}_{2}-\mathrm{XX}, 12 \%$ in $\mathrm{MT}+\mathrm{E}_{2}-\mathrm{XY}$ and $8 \%$ in both were up-regulated; $56 \%$ in $\mathrm{MT}+\mathrm{E}_{2}-\mathrm{XX}$, $73 \%$ in $\mathrm{MT}+\mathrm{E}_{2}-\mathrm{XY}$ and $48 \%$ in both displayed no change; $27 \%$ in $\mathrm{MT}+\mathrm{E}_{2}-\mathrm{XX}, 15 \%$ in $\mathrm{MT}+\mathrm{E}_{2}-\mathrm{XY}$ and $9 \%$ in both were down-regulated (Fig. 4D). Of the M-UPGs 3\% in MT+ $\mathrm{E}_{2}-\mathrm{XX}, 1 \%$ in $\mathrm{MT}+\mathrm{E}_{2}-\mathrm{XY}$ and $0.5 \%$ in both were upregulated compared with Ctrl-XY; and $21 \%$ in $\mathrm{MT}+\mathrm{E}_{2}-\mathrm{XX}$, $11 \%$ in $\mathrm{MT}+\mathrm{E}_{2}-\mathrm{XY}$ and $7 \%$ in both displayed no change; in contrast, consistent with the ovarian phenotype, 76\% in $\mathrm{MT}+\mathrm{E}_{2}-\mathrm{XX}, 88 \%$ in $\mathrm{MT}+\mathrm{E}_{2}-\mathrm{XY}$ and $73 \%$ in both were down-regulated (Fig. 4E).

In general, the expression profiles of most genes, especially foxl2, cyp19a1a, nanos3, dnd, dmrt1 and gsdf, were consistent with their ovarian phenotype in both $\mathrm{MT}+\mathrm{E}_{2}-\mathrm{XX}$ and $\mathrm{MT}+\mathrm{E}_{2}-\mathrm{XY}$ (Fig. S2, see section on supplementary data given at the end of this article).
Surprisingly, there were still minority of genes including $i g f 3, c y p 19 a 1 b, w t 1 b$ and some ribosome genes, displayed disrupted expression profile, were inconsistent with their ovarian phenotype (Fig. S3).

\section{MT and $E_{2}$ treatment on expression profiles of DNMT genes in gonads}

The expression level of maintenance methyltransferase gene dnmt1 was significantly up-regulated in both MT+ $\mathrm{E}_{2}-\mathrm{XX}$ and $\mathrm{MT}+\mathrm{E}_{2}-\mathrm{XY}$ gonads compared with the Ctrl$\mathrm{XX}, \mathrm{Ctrl}-\mathrm{XY}, \mathrm{MT}-\mathrm{XX}$ and $\mathrm{E}_{2}-\mathrm{XY}$ gonads which displayed no significant difference among them. The expression levels of de novo DNMTs genes dnmt3 and dnmt7 were down-regulated in the $\mathrm{MT}+\mathrm{E}_{2}-\mathrm{XX}$ gonad while upregulated in the $\mathrm{MT}+\mathrm{E}_{2}-\mathrm{XY}$ gonad compared with their respective control. However, the expression levels of de novo DNMTs genes dnmt4, dnmt6 and dnmt8 were downregulated in the $\mathrm{MT}+\mathrm{E}_{2}-\mathrm{XY}$ gonad compared with the Ctrl-XY and these genes displayed no significant difference in expression level between the $\mathrm{MT}+\mathrm{E}_{2}-\mathrm{XX}$ and the Ctrl-XX gonad (Fig. 5). Consistently, similar expression profiles of selected DNMTs genes were observed by real-time PCR. Some genes, such as igf $3, c y p 19 a 1 b, w t 1 b$, dnmt1, dnmt 3 and dnmt7 were selected for validation of
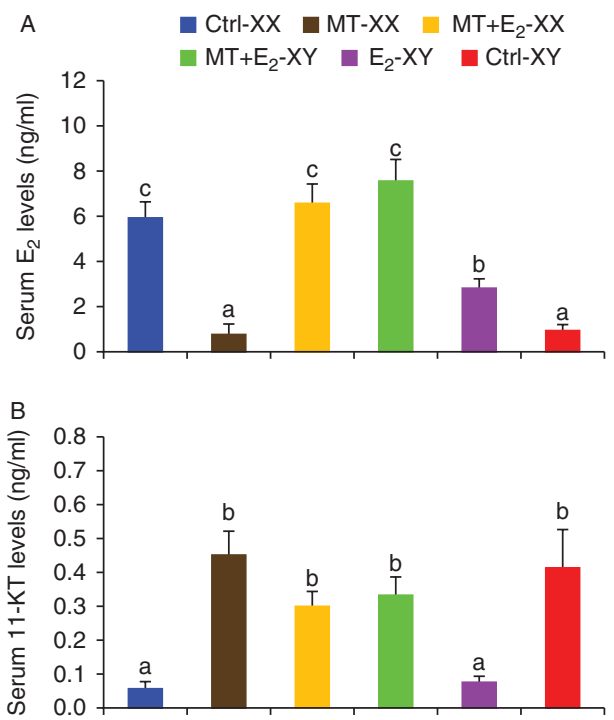

Figure 3

Serum $E_{2}(A)$ and 11-KT (B) level in MT-XX, $E_{2}-X Y, M T+E_{2}-X X, M T+E_{2}-X Y$, Ctrl-XX and Ctrl-XY fish at 90 dah by enzyme immunoassay. The fish were treated from 0 to 30 dah and then fed with control diet to 90 dah. Data were expressed as the mean \pm S.E.M. $(n=6)$. Different letters above the error bar indicate significant difference $(P<0.05)$ as determined by one-way ANOVA followed by post-hoc analysis. A full colour version of this figure is available at $\mathrm{http}: / / \mathrm{dx}$.doi.org/10.1530/JOE-15-0432.

Published by Bioscientifica Ltd 


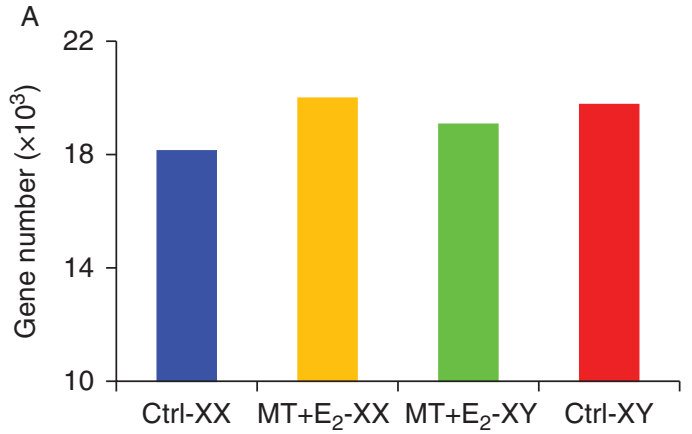

B

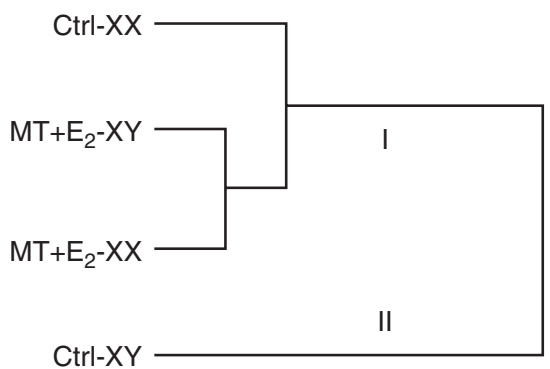

C

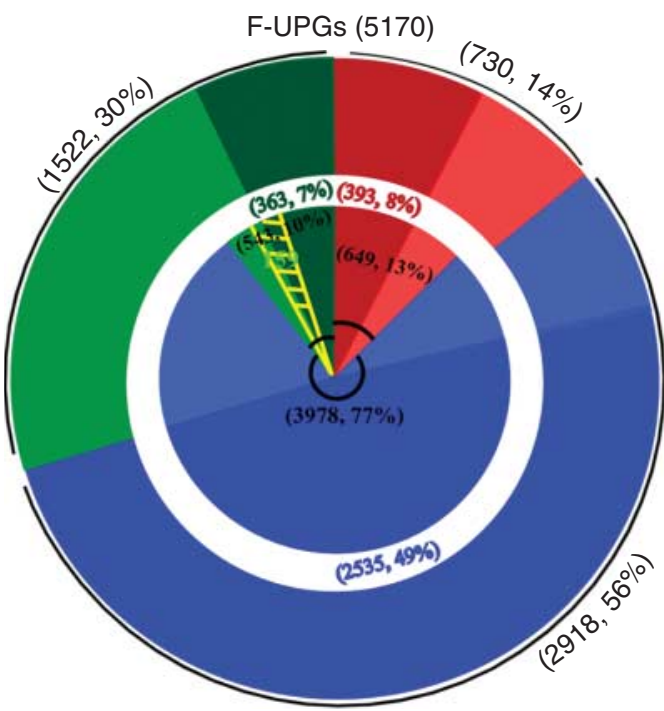

Red: genes up-regulated

Blue: genes non-differentially expressed

Green: genes down-regulated

\section{F/M-NDGs (5662)}

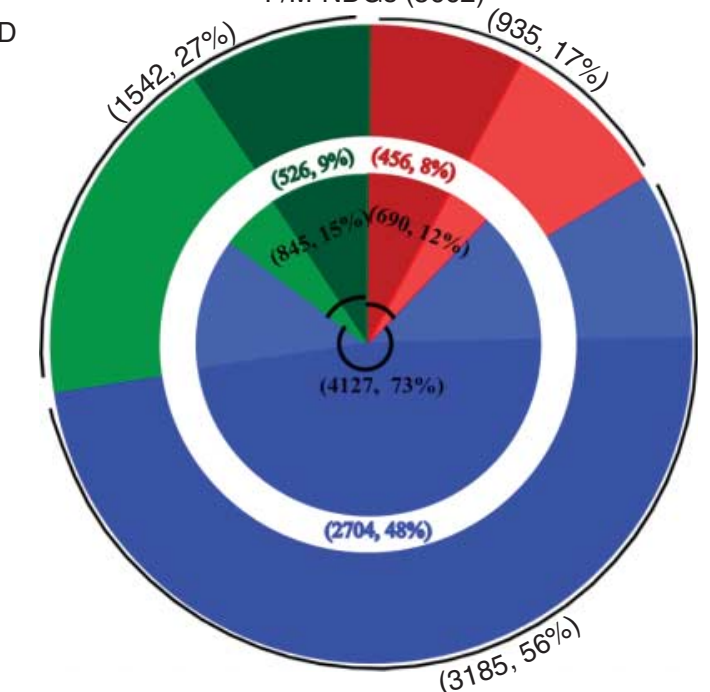

$\mathrm{E}$

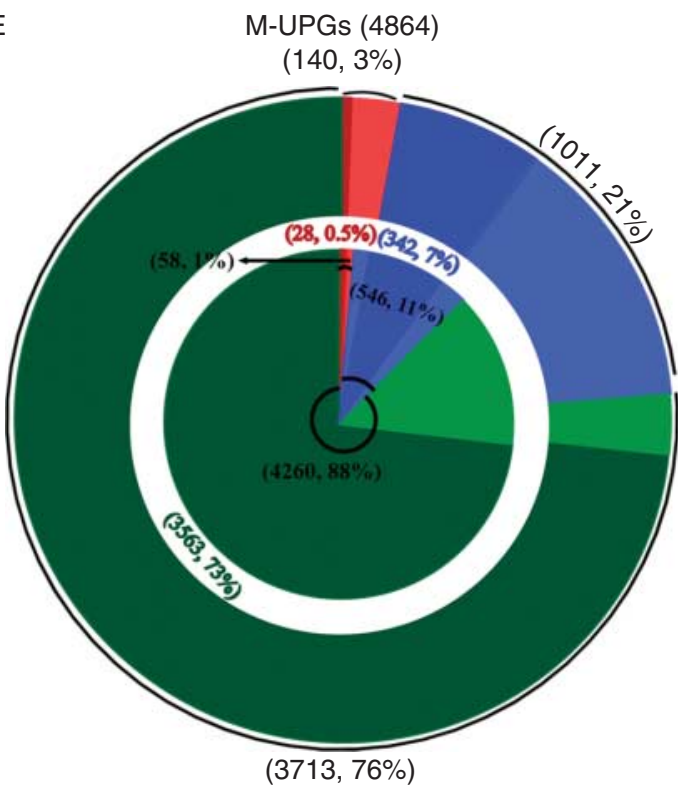

$7 \%$ in both were down-regulated. Of the F/M-NDGs $17 \%$ in MT+ $\mathrm{E}_{2}-\mathrm{XX}$, $12 \%$ in $\mathrm{MT}+\mathrm{E}_{2}-\mathrm{XY}$ and $8 \%$ in both were up-regulated; $56 \%$ in $\mathrm{MT}+\mathrm{E}_{2}-\mathrm{XX}$ $73 \%$ in $\mathrm{MT}+\mathrm{E}_{2}-\mathrm{XY}$ and $48 \%$ in both still displayed no change; $27 \%$ in $\mathrm{MT}+$ $E_{2}-X X, 15 \%$ in $M T+E_{2}-X Y$ and $9 \%$ in both were down-regulated. Of the $\mathrm{M}$-UPGs $3 \%$ in $\mathrm{MT}+\mathrm{E}_{2}-\mathrm{XX}, 1 \%$ in $\mathrm{MT}+\mathrm{E}_{2}-\mathrm{XY}$ and $0.5 \%$ in both were up-regulated; $21 \%$ in $\mathrm{MT}+\mathrm{E}_{2}-\mathrm{XX}, 11 \%$ in $\mathrm{MT}+\mathrm{E}_{2}-\mathrm{XY}$ and $7 \%$ in both still displayed no change; $76 \%$ in $\mathrm{MT}+\mathrm{E}_{2}-\mathrm{XX}, 88 \%$ in $\mathrm{MT}+\mathrm{E}_{2}-\mathrm{XY}$ and $73 \%$ in both were down-regulated. Outside and inside pie represent gene expression profile of $M T+E_{2}-X X$ and $M T+E_{2}-X Y$ respectively. Light and dark colors represent different and shared genes between $M T+E_{2}-X X$ and $\mathrm{MT}+\mathrm{E}_{2}-\mathrm{XY}$ respectively.

Published by Bioscientifica Ltd http://joe.endocrinology-journals.org DOI: 10.1530/JOE-15-0432
(C) 2016 Society for Endocrinology Printed in Great Britain 


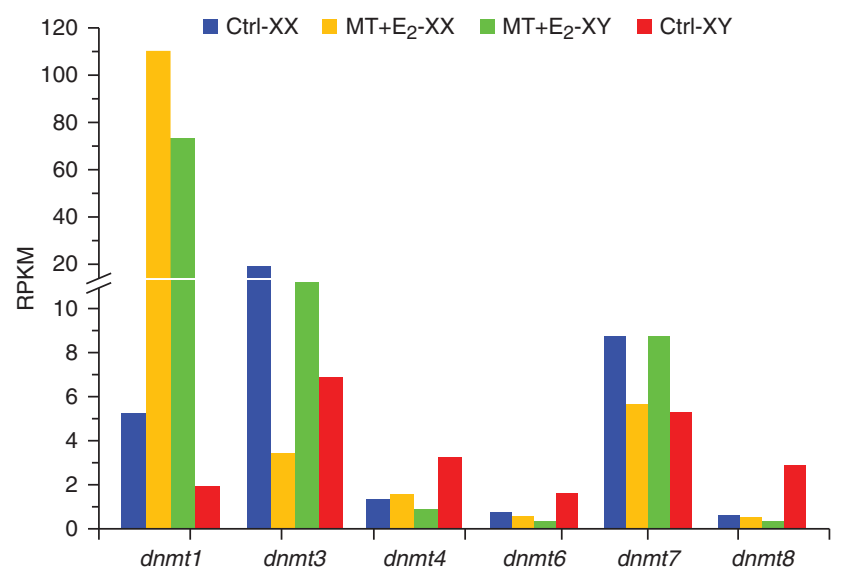

Figure 5

Expression profiles of methyltransferase genes in gonads. The expression levels of the maintenance methyltransferase gene dnmt 1 were up-regulated significantly, while the expression levels of the de novo DNA methyltransferases genes $d n m t 3$ and $d n m t 7$ were down-regulated in the $\mathrm{MT}+\mathrm{E}_{2}-\mathrm{XX}$ gonad but up-regulated in the $\mathrm{MT}+\mathrm{E}_{2}-\mathrm{XY}$ gonad significantly compared with their respective control. However, the expression levels of the de novo DNA methyltransferases genes dnmt4, dnmt6 and dnmt8 were down-regulated in $\mathrm{MT}+\mathrm{E}_{2}-\mathrm{XY}$ gonad compared with the Ctrl-XY and they displayed no significant change in the $\mathrm{MT}+\mathrm{E}_{2}-\mathrm{XX}$ gonad compared with the Ctrl-XX. A full colour version of this figure is available at http://dx.doi. org/10.1530/JOE-15-0432.

transcriptome data with qPCR. Comparison of the transcriptome data with the qPCR results revealed similar expression profiles (Fig. 6).

\section{Discussion}

\section{Sex was determined by estrogen even in the presence of androgen}

Many studies have been focused on the role of sex hormones during gonadal sex differentiation. Genetic males can be reversed to phenotypic females with estrogens if the treatment is applied before sex differentiation in vertebrates including marsupials (Coveney et al. 2001), birds (Scheib 1983), reptiles (Merchant-Larios et al. 1997), and teleosts (Kobayashi et al. 2003, Baron et al. 2004, Gennotte et al. 2014). In species with natural sex reversal, increase of serum $\mathrm{E}_{2}$ levels always associated with male to female sex reversal in protandrous fish (Guiguen et al. 1993). In contrast, $\mathrm{E}_{2}$ levels have been found to decrease during female to male sex reversal in protogynous fish (Yeung \& Chan 1987, Nakamura et al. 1989). Repression of aromatase expression and decrease of estrogen level were also observed in female to male sex reversal induced by high rearing temperatures ( $\mathrm{D}^{\prime} \mathrm{Cotta}$ et al. 2001). Long-term treatment of aromatase inhibitor
Fadrozole even induced secondary sex reversal of the differentiated ovary into functional testis (Paul-Prasanth et al. 2013, Sun et al. 2014). However, it is unclear whether sex will still be determined by estrogen if the animals were exposed to an environment with both estrogens and androgens. In this study, MT treatment induced 100\% sex reversal of all XX fish, and Cyp19a1a was detected in gonads at 5 and 10 dah while disappeared from 30 dah onwards. However, MT $+\mathrm{E}_{2}$ treatment of XX fish resulted in no sex reversal at all, and the expression of cyp19a1a were detected in gonads at all time points checked, indicating that estrogen is responsible for the maintenance of female phenotype and androgen cannot induce sex reversal in the presence of estrogen. On the other hand, no significant differences in the percentage of sex reversal were observed between the $\mathrm{E}_{2}-\mathrm{XY}(63 \%)$ and the $\mathrm{MT}+\mathrm{E}_{2}-\mathrm{XY}(52 \%)$ fish indicating that estrogen can still induce sex reversal even in the presence of androgen. The remaining 37 and $48 \%$ of the $\mathrm{E}_{2}-\mathrm{XY}$ and $\mathrm{MT}+\mathrm{E}_{2}-\mathrm{XY}$ fish developed into male which might be caused by different sensitivity of these fish to steroid treatment. As we all know, the continuity of species is largely dependent on female population. Giving priority to female may be the result of natural selection. Taken together, our results highlight the crucial role of estrogen in sex differentiation and maintenance in non-mammalian vertebrates.

Estrogen is synthesized earlier in females than androgen in males during sex differentiation. Consequently, sex differentiation and meiosis initiate earlier in female than in male. Consistently, in the present study, the expression of cyp19a1a started earlier in the Ctrl-XX and $\mathrm{MT}+\mathrm{E}_{2}-\mathrm{XX}$ (5 dah) female or the sex reversed $\mathrm{E}_{2}-\mathrm{XY}$ and $\mathrm{MT}+\mathrm{E}_{2}-\mathrm{XY}(10 \mathrm{dah})$ female than the expression of $c y p 11 b 2$ in the Ctrl-XY male or the sex reversed MT-XX (30 dah) male, and meiosis initiate earlier in the normal and sex reserved female ( $30 \mathrm{dah})$ than in the normal and sex reserved male (85 dah) (Kobayashi \& Nagahama 2009). One possible explanation might be that oogenesis takes more time than spermatogenesis as the oocytes need to deposit bulk nutrients for the developing embryos which is time consuming.

The earlier occurrence of ovarian differentiation than testicular differentiation in vertebrates gives the impression that it should be easier to induce male to female sex reversal. However, this is opposite to the facts: i) it is easy to induce $100 \%$ female to male sex reversal but it is difficult to induce $100 \%$ male to female sex reversal and ii) secondary sex reversal of ovary into testis has been reported in medaka, zebrafish and tilapia (Poonlaphdecha et al. 2013, Takatsu et al. 2013, Sun et al. 2014), while there

Published by Bioscientifica Ltd 


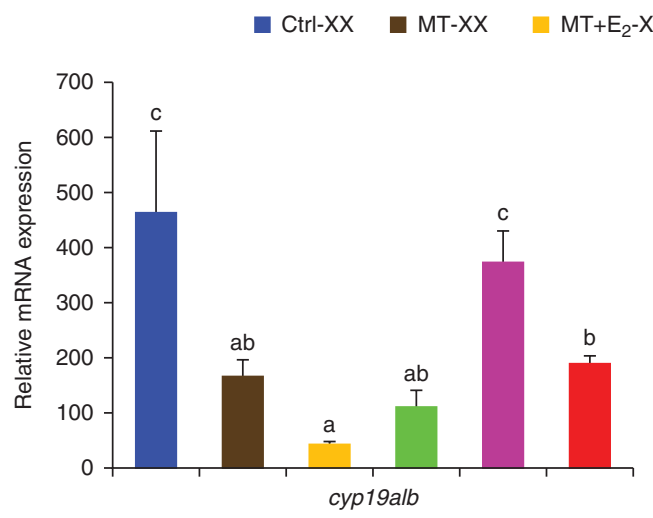

$\square \mathrm{MT}+\mathrm{E}_{2}-\mathrm{XY} \quad \square \mathrm{E}_{2}-\mathrm{XY} \quad \boldsymbol{\mathrm { Ctrl }}-\mathrm{XY}$
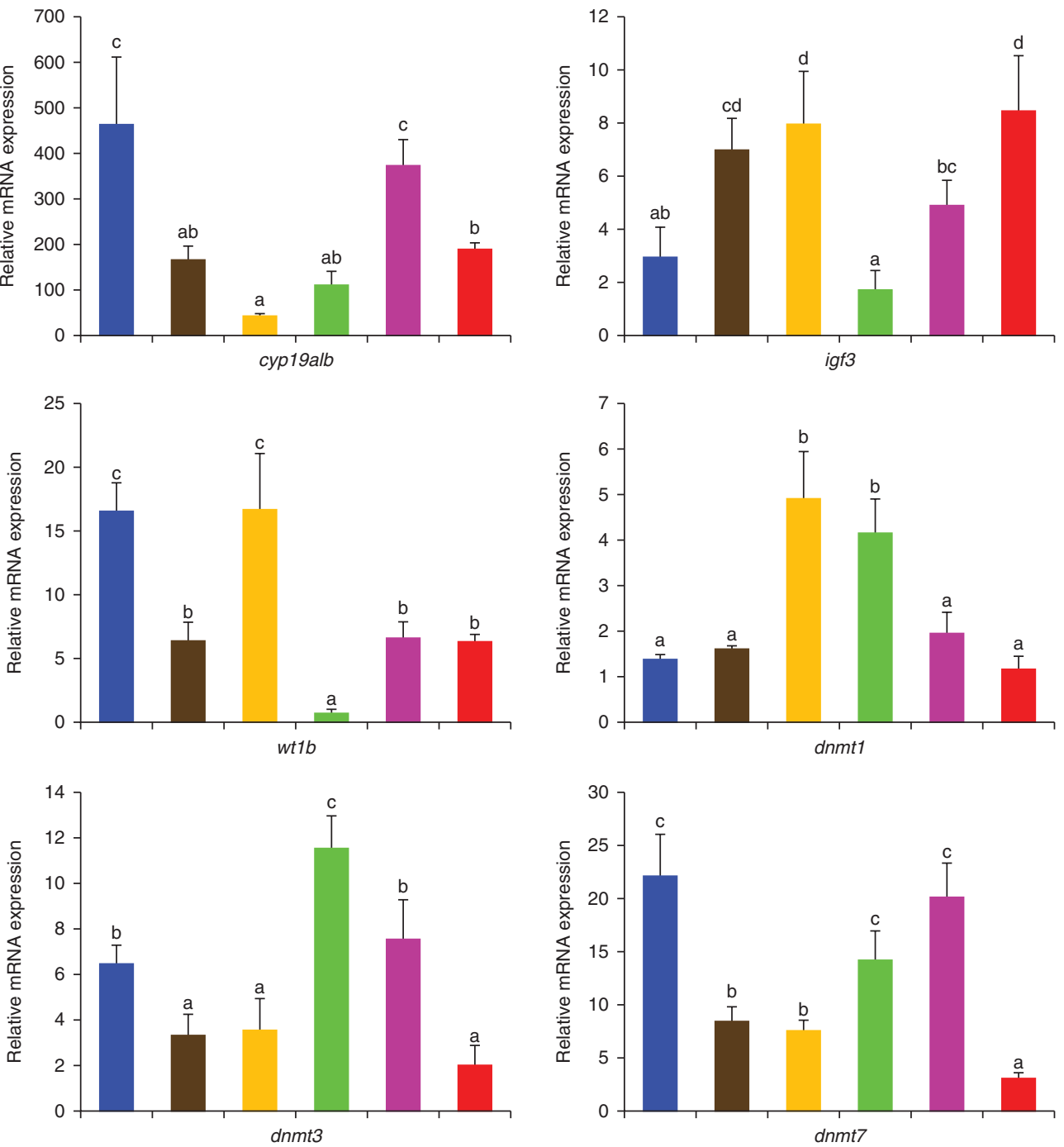

\section{Figure 6}

Validation of genes with disrupted expression profile from transcriptome data by real-time PCR. All examined genes displayed similar expression profiles to those from the transcriptome data. Data were expressed as the mean \pm S.E.M. $(n=6)$. Different letters above the error bar indicate

has been no report showing the successful sex reversal of a testis into an ovary in teleosts. In fact, high doses of $\mathrm{E}_{2}$ treatment are needed to induce complete male to female sex reversal in rainbow trout, tilapia and other teleosts (Krisfalusi \& Nagler 2000, Bhandari et al. 2005, Gennotte et al. 2014). This might be explained by the following two possible reasons: i) though the ovarian differentiation occurs earlier than testicular differentiation, the male determining gene, such as amhy in tilapia, expresses even earlier than the female pathway genes (Eshel et al. 2014, Li et al. 2015a,b), and therefore high doses of $\mathrm{E}_{2}$ are needed significant difference $(P<0.05)$ as determined by one-way ANOVA followed by post-hoc analysis. A full colour version of this figure is available at http://dx.doi.org/10.1530/JOE-15-0432.

to antagonize the male pathway genes, which is further supported by the differential sensitivity of $\mathrm{XY}$ and $\mathrm{YY}$ genotypes to embryonic induced-feminization (Gennotte et al. 2014); and ii) almost all steroidogenic enzyme genes are expressed in XX gonads but not in XY gonads at 5 dah (Tao et al. 2013), and therefore high doses of $\mathrm{E}_{2}$ are needed to induce those genes, especially cyp19a1a, expression for ovarian differentiation.

Signals of Dmrt1 and Cyp19a1a could be simultaneously detected at 10 dah in the MT-XX gonad while Cyp19a1a disappeared latter on. Granulosa cell marker 
Cyp19a1a was down-regulated while Sertoli cell marker Dmrt1 was up-regulated following androgen treatment, indicating the de-differentiation of the granulosa cells and then trans-differentiation into Sertoli cells as suggested in rainbow trout (Baron et al. 2008). Similarly, signals of Dmrt1 and Cyp19a1a could be simultaneously detected at 10 dah in $\mathrm{E}_{2}-\mathrm{XY}$ and $\mathrm{MT}+\mathrm{E}_{2}-\mathrm{XY}$ fish while Dmrt1 disappeared latter on. There would be a process for the de-differentiation of the Sertoli cells and then transdifferentiation into granulosa cells.

There have been many publications showing that ovarian pathway operates by repressing the testicular pathway, e.g. estrogen treatment resulted in downregulation of $\mathrm{P} 45011 \beta, 3 \beta \mathrm{HSD}$ and $\mathrm{P} 450 \mathrm{c} 17$, and thus inhibition of the synthesis of testicular androgen. This was suggested as an important step required for the feminization of genetic male fish (Govoroun et al. 2001). On the other hand, there have been reports showing that inhibition of estrogen synthesis by aromatase inhibitors or androgen resulted in female to male sex reversal (Baron et al. 2007, Poonlaphdecha et al. 2013, Sun et al. 2014). The two opposite pathways are continuously antagonizing during development as demonstrated by the simultaneous expression of cyp19a1a and dmrt1 during sex reversal in the present study and by the simultaneous expression of cyp19a1a and cyp11b2 during secondary sex reversal (Sun et al. 2014). The antagonism is also reflected by sex reversal after mutation of the key genes, such as foxl2 and dmrt1, of the female and male pathway (Li et al. 2013, Boulanger et al. 2014, Lindeman et al. 2015).

The function of androgen in sex differentiation is controversial. It has been long believed that the sex of fish is determined by the dominate steroids. In general, estrogens feminize genetic males and androgens masculinize genetic females (Devlin \& Nagahama 2002). This was confirmed by the wide use of steroids for sex reversal in fish. However, lines of evidences demonstrated that the undifferentiated male gonads could synthesize neither estrogens nor androgens (Guiguen et al. 1999, Nagahama 2000, Tao et al. 2013). Interestingly, in the present study, Cyp11b2 was detected from 30 dah in $\mathrm{MT}+\mathrm{E}_{2}-\mathrm{XX}$ and $\mathrm{MT}+\mathrm{E}_{2}-\mathrm{XY}$ gonads which were developed into ovaries, indicating that MT treatment resulted in endogenous androgen synthesis and both exogenous and endogenous androgens were not involved in sex differentiation in the presence of estrogen. The masculinization of female by androgen could be explained by two evidences. One is that androgen receptors are expressed in XX gonads at a time critical for sex determination in tilapia (Tao et al. 2013); the other is that androgens probably act as an inhibitor of female pathway and $\mathrm{E}_{2}$ synthesis (Bhandari et al. 2006, Vizziano et al. 2008). The male's main role is the production of sperm, which is critical for improving population viability via sexual selection in the face of genetic stress as demonstrated recently in the flour beetle (Lumley et al. 2015). It is well documented that androgen is essential for spermatogenesis (Billard et al. 1982, Ruwanpura et al. 2010).

\section{Simultaneous treatment of $\mathrm{MT}$ and $\mathrm{E}_{2}$ resulted in endocrine disruption and disorder of gene expression}

Surprisingly, no differences in the serum 11-KT level were observed among $\mathrm{MT}+\mathrm{E}_{2}-\mathrm{XX}, \mathrm{MT}+\mathrm{E}_{2}-\mathrm{XY}$ and Ctrl-XY fish though the former two were female with typical ovaries. Consistently, cyp11b2 and cyp19a1a were co-expressed in the interstitial cells of ovaries in both groups, indicating that steroidogenesis of these fish were disrupted when androgen and estrogen exist simultaneously in the environment. One possible explanation might be that the environmental estrogens and androgens mimic the natural ones and disrupt the endocrine system of aquatic animals as suggested previously by other researchers (Guillette \& Gunderson 2001). Endogenous hormones could activate nuclear receptors and then regulate the expression of a sizable proportion of genes would have profound effects on the organisms (Li et al. 2015a,b). Our results showed that most of the genes in both $\mathrm{MT}+\mathrm{E}_{2}-\mathrm{XX}$ and $\mathrm{MT}+\mathrm{E}_{2}-\mathrm{XY}$ gonads displaying expression profile consistent with ovarian phenotype. Such as high expression of foxl2, cyp19a1a, nanos3, dnd and fig1a which are key genes involved in ovarian differentiation and development, and low expression of dmrt1, gsdf, sf1 and amh which are key genes involved in testicular differentiation and development (Baron et al. 2008, Ijiri et al. 2008, Li et al. 2013, Tao et al. 2013, Poonlaphdecha et al. 2013). Expression profiles of many genes such as pin1, $i g f 2 r$, rspondin1, ar $\alpha$ and $\operatorname{er} \beta$ displayed no significant difference between $\mathrm{MT}+\mathrm{E}_{2}-\mathrm{XX}, \mathrm{MT}+\mathrm{E}_{2}-\mathrm{XY}$, Ctrl-XX and Ctrl-XY, indicating their essential roles in gonadal development, but not in sex differentiation. There was consistent report showing that pin1 is involved in the regulation of mammalian primordial germ cells proliferation in both male and female (Atchison et al. 2003). However, a small fraction of genes in both $\mathrm{MT}+\mathrm{E}_{2}-\mathrm{XX}$ and $\mathrm{MT}+\mathrm{E}_{2}-\mathrm{XY}$ displayed inconsistent expression profile with their ovarian phenotypes, indicating that these genes are not involved in sex differentiation. It is well documented that differences exist between the sexes in their response to environmental stress and females are more influenced

Published by Bioscientifica Ltd. 
by environmental cues and stress (Senovilla et al. 2008, Bertholomey \& Torregrossa 2015, Speed et al. 2015). Consistently, in the present study, there were more genes in $\mathrm{MT}+\mathrm{E}_{2}-\mathrm{XX}(27 \%)$ than in $\mathrm{MT}+\mathrm{E}_{2}-\mathrm{XY}(16 \%)$ displayed expression profile inconsistent with their ovarian phenotypes. The expression level of some genes, such as vasa and many ribosome genes, were significantly up-regulated while dazap2 were significantly downregulated compared with both Ctrl-XX and Ctrl-XY, indicating that they might be involved in stress response in both male and female. vasa, the molecular marker of the germ line lineage in many organisms, has been reported to be up-regulated by u.v. radiation stress in Botryllus schlosseri (Rosner et al. 2009). The up-regulation of ribosome genes has also been reported in rainbow trout by androgen treatment (Baron et al. 2007) and in shortlived fish by diapauses (Reichwald et al. 2015). dazap2 has been reported to induce stress granules formation in mouse (Kim et al. 2008). The expression of some genes, such as some ribosome genes, were significantly changed only in $\mathrm{MT}+\mathrm{E}_{2}-\mathrm{XX}$, and some others, such as sparc, igf3 and $w t 1 b$, only in $\mathrm{MT}+\mathrm{E}_{2}-\mathrm{XY}$, which may be involved in genetic female and male stress response respectively. Some of the highly expressed ribosome genes are also reported to be involved in abiotic stress responses (Wang et al. 2013). sparc has been reported to play a key role in post-synthetic procollagen processing in normal and pressure-overloaded myocardium of mice (Bradshaw et al. 2009). The expression of $w t 1 b$, an epicardial gene in zebrafish, is responsive to heart injury (Itou et al. 2012). Estrogen treatments resulted in significant down-regulation of igf 3 mRNA in the testis while ovarian igf3 mRNA did not respond (Berishvili et al. 2010), in contrast, androgens increased igf3 transcript levels in the ovary (Melo et al. 2015). In our study, igf3 was down-regulated significantly in $\mathrm{E}_{2}-\mathrm{XY}$ and $\mathrm{MT}+\mathrm{E}_{2}-\mathrm{XY}$ compared with Ctrl-XY, while up-regulated significantly in $\mathrm{MT}-\mathrm{XX}$ and $\mathrm{MT}+\mathrm{E}_{2}-\mathrm{XX}$ compared with Ctrl-XX. These results demonstrated that simultaneous treatment with estrogen and androgen resulted in severe endocrine disruption.

It has long been proposed that epigenetic regulation may play an important role in ESD species in response to environmental influences, leading to the gonad developmental change (Manolakou et al. 2006). Plenty of experiment results suggested that epigenetic regulation plays multiple crucial roles in the gonadal differentiation of teleosts and other vertebrates (Navarro-Martin et al. 2011, Zhang et al. 2013, Parrott et al. 2014, Shao et al. 2014). Neonatal exposure to the synthetic estrogen diethylstilbestrol caused abnormal demethylation of the
CpG sites upstream of the estrogen-response element of the lactoferrin promoter (Li et al. 1997). In the present study, the de novo methyltransferase dnmt6, dnmt8 and dnmt4, which are counterparts of mammalian dnmt3a and dnmt3b, displayed the same expression pattern in the Ctrl-XX, $\mathrm{MT}+\mathrm{E}_{2}-\mathrm{XX}$ and $\mathrm{MT}+\mathrm{E}_{2}-\mathrm{XY}$ ovary, while different from that of the Ctrl-XY testis. One possible explanation is estrogen determines sex by influencing the expression of methyltransferase, which in turn, result in the change of gene expression pattern that in favor of the female pathway. Surprisingly, the expression level of maintenance methyltransferase gene dnmt1 was significantly up-regulated in the gonads of $\mathrm{MT}+\mathrm{E}_{2}-\mathrm{XX}$ and $\mathrm{MT}+\mathrm{E}_{2}-\mathrm{XY}$ compared with Ctrl-XX and Ctrl-XY, implying that animals might be able to adapt to the endocrine disruptor polluted environment by change of the gene expression pattern via the up- or down-regulation of methyltransferase gene expression.

In summary, estrogen could feminize XY fish even in the presence of androgen, while androgen could not masculinize XX fish in the presence of estrogen. These results strongly emphasize the critical role of estrogen in sex differentiation and maintenance in teleosts. Simultaneous treatment with estrogen and androgen up-regulated the endogenous estrogen and androgen syntheses, and resulted in disordered gene expression and endocrine disruption. Our study provided a very useful model for the understanding of the molecular mechanism of animals adapt to the estrogen and androgen contaminated environments.

\section{Supplementary data}

This is linked to the online version of the paper at http://dx.doi.org/10.1530/ JOE-15-0432.

\section{Declaration of interest}

The authors declare that there is no conflict of interest that could be perceived as prejudicing the impartiality of the research reported.

\section{Funding}

This work was supported by the National Natural Science Foundation of China (grant numbers 91331119 and 31030063); the National Basic Research Program of China (grant number 2012CB723205); the National High Technology Research and Development Program (863 program) of China (grant number 2011AA100404); the Specialized Research Fund for the Doctoral Program of Higher Education of China (grant number 20130182130003); the Natural Science Foundation Project of Chongqing, Chongqing Science and Technology Commission (grant numbers cstc2013kjrc-tdjs80003); and the Fundamental Research Funds for the Central Universities (grant number XDJK2014B040).

Published by Bioscientifica Ltd 


\section{Author contribution statement}

Conceived and designed the experiments: $L C$ and $X J$; collected sample: $L C, X J, H F, Q X$ and $H S$; performed the experiments: $L C, X J$ and $H F$; performed the analyses: $L C, W T$ and $L S$; wrote the paper: D W, LC and LS.

\section{Data accessibility}

The RNA-seq reads reported in this study have been deposited in the National Center for Biotechnology Information Short Reads Archive, www. ncbi.nlm.nih.gov/sra (study accession ID: SRP063372).

\section{References}

Atchison FW, Capel B \& Means AR 2003 Pin1 regulates the timing of mammalian primordial germ cell proliferation. Development 130 3579-3586. (doi:10.1242/dev.00584)

Baron D, Cocquet J, Xia X, Fellous M, Guiguen Y \& Veitia RA 2004 An evolutionary and functional analysis of FoxL2 in rainbow trout gonad differentiation. Journal of Molecular Endocrinology 33 705-715. (doi:10.1677/jme.1.01566)

Baron D, Montfort J, Houlgatte R, Fostier A \& Guiguen Y 2007 Androgeninduced masculinization in rainbow trout results in a marked dysregulation of early gonadal gene expression profiles. BMC Genomics 8 357. (doi:10.1186/1471-2164-8-357)

Baron D, Houlgatte R, Fostier A \& Guiguen Y 2008 Expression profiling of candidate genes during ovary-to-testis trans-differentiation in rainbow trout masculinized by androgens. General and Comparative Endocrinology 156 369-378. (doi:10.1016/j.ygcen.2008.01.016)

Berishvili G, Baroiller JF, Eppler E \& Reinecke M 2010 Insulin-like growth factor-3 (IGF-3) in male and female gonads of the tilapia: development and regulation of gene expression by growth hormone $(\mathrm{GH})$ and 17 $\alpha$-ethinylestradiol $\left(\mathrm{EE}_{2}\right)$. General and Comparative Endocrinology 167 128-134. (doi:10.1016/j.ygcen.2010.01.023)

Bertholomey M \& Torregrossa M 2015 Female rats are more sensitive to enhanced reinstatement of alcohol seeking following exposure to both alcohol-related cues and yohimbine. Poster 1019.8 presented at Experimental Biology 2015, Boston, MA, USA. FASEB 29 (1 Supplement) 1019.8. (available at: http://www.fasebj.org/content/ 29/1_Supplement/1019.8.abstract)

Bhandari RK, Alam MA, Higa M, Soyano K \& Nakamura M 2005 Evidence that estrogen regulates the sex change of honeycomb grouper (Epinephelus merra), a protogynous hermaphrodite fish. Journal of Experimental Zoology. Part A, Comparative Experimental Biology 303 497-503. (doi:10.1002/jez.a.178)

Bhandari RK, Nakamura M, Kobayashi T \& Nagahama Y 2006 Suppression of steroidogenic enzyme expression during androgen-induced sex reversal in Nile tilapia (Oreochromis niloticus). General and Comparative Endocrinology 145 20-24. (doi:10.1016/j.ygcen.2005.06.014)

Billard R, Fostier A, Weil C \& Breton B 1982 Endocrine control of spermatogenesis in teleost fish. Canadian Journal of Fisheries and Aquatic Sciences 39 65-79. (doi:10.1139/f82-009)

Boulanger L, Pannetier M, Gall L, Allais-Bonnet A, Elzaiat M, Le Bourhis D, Daniel N, Richard C, Cotinot C, Ghyselinck NB et al. 2014 FOXL2 is a female sex-determining gene in the goat. Current Biology 24 404-408. (doi:10.1016/j.cub.2013.12.039)

Bradshaw AD, Baicu CF, Rentz TJ, Van Laer AO, Boggs J, Lacy JM \& Zile MR 2009 Pressure overload-induced alterations in fibrillar collagen content and myocardial diastolic function: role of secreted protein acidic and rich in cysteine (SPARC) in post-synthetic procollagen processing. Circulation 119 269-280. (doi:10.1161/CIRCULATIONAHA.108. 773424)
Coveney D, Shaw G \& Renfree MB 2001 Estrogen-induced gonadal sex reversal in the tammar wallaby. Biology of Reproduction 65 613-621. (doi:10.1095/biolreprod65.2.613)

D'Cotta H, Fostier A, Guiguen Y, Govoroun M \& Baroiller JF 2001 Aromatase plays a key role during normal and temperature-induced sex differentiation of tilapia Oreochromis niloticus. Molecular Reproduction and Development 59 265-276. (doi:10.1002/mrd.1031)

Devlin RH \& Nagahama Y 2002 Sex determination and sex differentiation in fish: an overview of genetic, physiological, and environmental influences. Aquaculture 208 191-364. (doi:10.1016/S00448486(02)00057-1)

Diamanti-Kandarakis E, Bourguignon JP, Giudice LC, Hauser R, Prins GS, Soto AM, Zoeller RT \& Gore AC 2009 Endocrine-disrupting chemicals: an Endocrine Society scientific statement. Endocrine Reviews 30 293-342. (doi:10.1210/er.2009-0002)

Eisen MB, Spellman PT, Brown PO \& Botstein D 1998 Cluster analysis and display of genome-wide expression patterns. PNAS 95 14863-14868. (doi:10.1073/pnas.95.25.14863)

Eshel O, Shirak A, Dor L, Band M, Zak T, Markovich-Gordon M, ChalifaCaspi V, Feldmesser E, Weller JI, Seroussi E et al. 2014 Identification of male-specific amh duplication, sexually differentially expressed genes and microRNAs at early embryonic development of Nile tilapia (Oreochromis niloticus). BMC Genomics 15 774. (doi:10.1186/14712164-15-774)

Gennotte V, Mélard C, D'Cotta H, Baroiller JF \& Rougeot C 2014 The sensitive period for male-to-female sex reversal begins at the embryonic stage in the Nile tilapia and is associated with the sexual genotype. Molecular Reproduction and Development 81 1146-1158. (doi:10.1002/ mrd.22436)

Govoroun M, McMeel OM, Mecherouki H, Smith TJ \& Guiguen Y 2001 $17 \beta$-estradiol treatment decreases steroidogenic enzyme messenger ribonucleic acid levels in the rainbow trout testis. Endocrinology $\mathbf{1 4 2}$ 1841-1848. (doi:10.1210/endo.142.5.8142)

Guiguen Y, Jalabert B, Thouard E \& Fostier A 1993 Changes in plasma and gonadal steroid hormones in relation to the reproductive cycle and the sex inversion process in the protandrous seabass, Lates calcarifer. General and Comparative Endocrinology 92 327-338. (doi:10.1006/gcen.1993. 1170)

Guiguen Y, Baroiller JF, Ricordel MJ, Iseki K, Mcmeel OM, Martin SA \& Fostier A 1999 Involvement of estrogens in the process of sex differentiation in two fish species: the rainbow trout (Oncorhynchus mykiss) and a tilapia (Oreochromis niloticus). Molecular Reproduction and Development 54 154-162. (doi:10.1002/(SICI)10982795(199910)54:2<154::AID-MRD7 > 3.0.CO;2-5)

Guillette LJ Jr \& Gunderson MP 2001 Alterations in development of reproductive and endocrine systems of wildlife populations exposed to endocrine-disrupting contaminants. Reproduction 122 857-864. (doi:10.1530/rep.0.1220857)

Hudson QJ, Smith CA \& Sinclair AH 2005 Aromatase inhibition reduces expression of FOXL2 in the embryonic chicken ovary. Developmental Dynamics 233 1052-1055. (doi:10.1002/dvdy.20388)

Ijiri S, Kaneko H, Kobayashi T, Wang DS, Sakai F, Paul-Prasanth B, Nakamura M \& Nagahama Y 2008 Sexual dimorphic expression of genes in gonads during early differentiation of a teleost fish, the Nile tilapia Oreochromis niloticus. Biology of Reproduction 78 333-341. (doi:10.1095/biolreprod.107.064246)

Itou J, Kawakami H, Burgoyne T \& Kawakami Y 2012 Life-long preservation of the regenerative capacity in the fin and heart in zebrafish. Open Biology 1 739-746. (doi:10.1242/bio.20121057)

Kim JE, Ryu I, Kim WJ, Song OK, Ryu J, Kwon MY, Kim JH \& Jang SK 2008 Proline-rich transcript in brain protein induces stress granule formation. Molecular and Cellular Biology 28 803-813. (doi:10.1128/MCB. 01226-07)

Kobayashi T \& Nagahama Y 2009 Molecular aspects of gonadal differentiation in a teleost fish, the Nile tilapia. Sexual Development 3 108-117. (doi:10.1159/000223076) 
Kobayashi T, Kajiura H, Chang X, Nakamura M \& Nagahama Y 1996 Antibodies against trout 3b-hydroxysteroid dehydrogenase: their preparation and immunocytochemical use for fishsteroidogenic tissue. Zoological Science 136.

Kobayashi T, Kajiura-Kobayashi H \& Nagahama Y 2003 Induction of XY sex reversal by estrogen involves altered gene expression in a teleost, tilapia. Cytogenetic and Genome Research 101 289-294. (doi:10.1159/ $000074351)$

Krisfalusi M \& Nagler JJ 2000 Induction of gonadal intersex in genotypic male rainbow trout (Oncorhynchus mykiss) embryos following immersion in estradiol-17 $\beta$. Molecular Reproduction and Development 56 495-501. (doi:10.1002/1098-2795(200008)56:4<495::AID-MRD7>3. $0 . \mathrm{CO} ; 2-\mathrm{E})$

La Salle S, Mertineit C, Taketo T, Moens PB, Bestor TH \& Trasler JM 2004 Windows for sex-specific methylation marked by DNA methyltransferase expression profiles in mouse germ cells. Developmental Biology 268 403-415. (doi:10.1016/j.ydbio.2003.12.031)

Li S, Washburn KA, Moore R, Uno T, Teng C, Newbold RR, McLachlan JA \& Negishi M 1997 Developmental exposure to diethylstilbestrol elicits demethylation of estrogen-responsive lactoferrin gene in mouse uterus. Cancer Research 57 4356-4359.

Li M, Wu F, Gu Y, Wang T, Wang H, Yang S, Sun Y, Zhou L, Huang X, Jiao B et al. 2012 Insulin-like growth factor 3 regulates expression of genes encoding steroidogenic enzymes and key transcription factors in the Nile tilapia gonad. Biology of Reproduction 86 163. (doi:10.1095/ biolreprod.111.096248)

Li MH, Yang HH, Li MR, Sun YL, Jiang XL, Xie QP, Wang TR, Shi HJ, Sun LN, Zhou LY et al. 2013 Antagonistic roles of Dmrt1 and Foxl2 in sex differentiation via estrogen production in tilapia as demonstrated by TALENs. Endocrinology 154 4814-4825. (doi:10.1210/en.2013-1451)

Li L, Wang Q, Zhang Y, Niu Y, Yao X \& Liu H 2015a The molecular mechanism of bisphenol A (BPA) as an endocrine disruptor by interacting with nuclear receptors: insights from molecular dynamics (MD) simulations. PLoS ONE 10 e0120330. (doi:10.1371/journal.pone. 0120330)

Li M, Sun Y, Zhao J, Shi H, Zeng S, Ye K, Jiang D, Zhou L, Sun L, Tao W et al. $2015 b$ A tandem duplicate of anti-Mullerian hormone with a missense SNP on the Y chromosome is essential for male sex determination in Nile tilapia, Oreochromis niloticus. PLoS Genetics 11 e1005678. (doi:10.1371/journal.pgen.1005678)

Lindeman RE, Gearhart MD, Minkina A, Krentz AD, Bardwell VJ \& Zarkower D 2015 Sexual cell-fate reprogramming in the ovary by DMRT1. Current Biology 25 764-771. (doi:10.1016/j.cub.2015.01.034)

Lumley AJ, Michalczyk L, Kitson JJ, Spurgin LG, Morrison CA, Godwin JL, Dickinson ME, Martin OY, Emerson BC, Chapman T et al. 2015 Sexual selection protects against extinction. Nature 10 1038. (doi:10.1038/ nature14419)

Manolakou P, Lavranos G \& Angelopoulou R 2006 Molecular patterns of sex determination in the animal kingdom: a comparative study of the biology of reproduction. Reproductive Biology and Endocrinology 459. (doi:10.1186/1477-7827-4-59)

Melo MC, van Dijk P, Andersson E, Nilsen TO, Fjelldal PG, Male R, Nijenhuis W, Bogerd J, de França LR, Taranger GL et al. 2015 Androgens directly stimulate spermatogonial differentiation in juvenile Atlantic salmon (Salmo salar). General and Comparative Endocrinology 211 52-61. (doi:10.1016/j.ygcen.2014.11.015)

Merchant-Larios H, Ruiz-Ramirez S, Moreno-Mendoza N \& MarmolejoValencia A 1997 Correlation among thermo sensitive period, estradiol response, and gonad differentiation in the sea turtle Lepidochelys olivacea. General and Comparative Endocrinology 107 373-385. (doi:10.1006/gcen.1997.6946)

Morrey CE, Nakamura M, Kobayashi T, Grau EG \& Nagahama Y 1998 P450scc-like immunoreactivity throughout gonadal restructuring in the protogynous hermaphrodite Thalassoma duperrey. International Journal of Developmental Biology 42 811-816.
Mortazavi A, Williams BA, McCue K, Schaeffer L \& Wold B 2008 Mapping and quantifying mammalian transcriptomes by RNA-Seq. Nature Methods 5 621-628. (doi:10.1038/nmeth.1226)

Nagahama Y 2000 Gonadal steroid hormones: major regulators of gonadal sex differentiation and gametogenesis in fish. Proceedings of 6th International Symposium on Reproductive Physiology of Fish, pp 211-222. Eds B Norberg, OS Kjesbu, GL Taranger, E Andersson \& SO Stefansson. Institute of Marine Research and University of Bergen: Bergen, Norway.

Nakamura M, Hourigan TF, Yamauchi K, Nagahama Y \& Grau G 1989 Histological and ultrastructural evidence for the role of gonadal steroid hormones in sex change in the protogynous wrasse Thalassoma duperrey. Environmental Biology of Fishes 24 117-136. (doi:10.1007/ BF00001282)

Navarro-Martin L, Vinas J, Ribas L, Diaz N, Gutierrez A, Di Croce L \& Piferrer F 2011 DNA methylation of the gonadal aromatase (cyp19a) promoter is involved in temperature dependent sex ratio shifts in the European sea bass. PLoS Genetics 7 e1002447. (doi:10.1371/journal. pgen.1002447)

Parrott BB, Kohno S, Cloy-McCoy JA \& Guillette LJ Jr 2014 Differential incubation temperatures result in dimorphic DNA methylation patterning of the SOX9 and aromatase promoters in gonads of alligator (Alligator mississippiensis) embryos. Biology of Reproduction 902. (doi:10.1095/biolreprod.113.111468)

Paul-Prasanth B, Bhandari RK, Kobayashi T, Horiguchi R, Kobayashi Y, Nakamoto M, Shibata Y, Sakai F, Nakamura M \& Nagahama Y 2013 Estrogen oversees the maintenance of the female genetic program in terminally differentiated gonochorists. Scientific Reports 32862. (doi:10.1038/srep02862)

Piferrer F 2013 Epigenetics of sex determination and gonadogenesis. Developmental Dynamics 242 360-370. (doi:10.1002/dvdy.23924)

Piferrer F, Zanuy S, Carrillo M, Solar DevlinRH II \& Donaldson EM 1994 Brief treatment with an aromatase inhibitor during sex differentiation causes chromosomally female salmon to develop as normal, functional males. Journal of Experimental Zoology 270 255-262. (doi:10.1002/jez. 1402700304)

Poonlaphdecha S, Pepey E, Canonne M, de Verdal H, Baroiller JF \& D'Cotta H 2013 Temperature induced-masculinisation in the Nile tilapia causes rapid up-regulation of both dmrt1 and amh expressions. General and Comparative Endocrinology 193 234-242. (doi:10.1016/j.ygcen.2013. 06.007)

Reichwald K, Petzold A, Koch P, Downie BR, Hartmann N, Pietsch S, Baumgart M, Chalopin D, Felder M, Bens M et al. 2015 Insights into sex chromosome evolution and aging from the genome of a short-lived fish. Cell 163 1527-1538. (doi:10.1016/j.cell.2015.10.071)

Rosner A, Moiseeva E, Rinkevich Y, Lapidot Z \& Rinkevich B 2009 Vasa and the germ line lineage in a colonial urochordate. Developmental Biology 331 113-128. (doi:10.1016/j.ydbio.2009.04.025)

Ruwanpura SM, McLachlan RI \& Meachem SJ 2010 Hormonal regulation of male germ cell development. Journal of Endocrinology 205 117-131. (doi:10.1677/JOE-10-0025)

Scheib D 1983 Effects and role of estrogens in avian gonadal differentiation. Differentiation 23 S87-S92.

Senovilla L, Núñez L, Villalobos C \& García-Sancho J 2008 Rapid changes in anterior pituitary cell phenotypes in male and female mice after acute cold stress. Endocrinology 149 2159-2167. (doi:10.1210/en. 2007-1030)

Shao C, Li Q, Chen S, Zhang P, Lian J, Hu Q, Sun B, Jin L, Liu S, Wang Z et al. 2014 Epigenetic modification and inheritance in sexual reversal of fish. Genome Research 24 604-615. (doi:10.1101/gr.162172.113)

Speed JS, D'Angelo G, Wach PA, Sullivan JC, Pollock JS \& Pollock DM 2015 High salt diet increases the pressor response to stress in female, but not male ETB-receptor-deficient rats. Physiological Reports 3 e12326. (doi:10.14814/phy2.12326)

Sun LN, Jiang XL, Xie QP, Yuan J, Huang BF, Tao WJ, Zhou LY, Nagahama Y \& Wang DS 2014 Transdifferentiation of differentiated 
ovary into functional testis by long-term treatment of aromatase inhibitor in Nile tilapia. Endocrinology 155 1476-1488. (doi:10.1210/en. 2013-1959)

Takatsu K, Miyaoku K, Roy SR, Murono Y, Sago T, Itagaki H, Nakamura M \& Tokumoto T 2013 Induction of female-to-male sex change in adult zebrafish by aromatase inhibitor treatment. Scientific Report 33400. (doi:10.1038/srep03400)

Tao W, Yuan J, Zhou L, Sun L, Sun Y, Yang S, Li M, Zeng S, Huang B \& Wang D 2013 Characterization of gonadal transcriptomes from Nile tilapia (Oreochromis niloticus) reveals differentially expressed genes. PLoS ONE 8 e63604. (doi:10.1371/journal.pone.0063604)

Vizziano D, Baron D, Randuineau G, Mahè S, Cauty C \& Guiguen Y 2008 Rainbow trout gonadal masculinization induced by inhibition of estrogen synthesis is more physiological than masculinization induced by androgen supplementation. Biology of Reproduction 78 939-946. (doi:10.1095/biolreprod.107.065961)
Wang J, Lan P, Gao H, Zheng L, Li W \& Schmidt W 2013 Expression changes of ribosomal proteins in phosphate- and iron-deficient Arabidopsis roots predict stress-specific alterations in ribosome composition. BMC Genomics 14 783. (doi:10.1186/1471-2164-14-783)

Wibbels T \& Crews D 1994 Putative aromatase inhibitor induces male sex determination in a female unisexual lizard and in a turtle with temperature-dependent sex determination. Journal of Endocrinology $\mathbf{1 4 1}$ 295-299. (doi:10.1677/joe.0.1410295)

Yeung WS \& Chan ST 1987 The plasma sex steroid profiles in the freshwater, sex-reversing teleost fish, Monopterus albus (Zuiew). General and Comparative Endocrinology 65 233-242. (doi:10.1016/00166480(87)90171-7)

Zhang Y, Zhang S, Liu Z, Zhang L \& Zhang W 2013 Epigenetic modifications during sex change repress gonadotropin stimulation of cyp19a1a in a teleost ricefield eel (Monopterus albus). Endocrinology 154 2881-2890. (doi:10.1210/en.2012-2220)

Received in final form 22 December 2015

Accepted 12 January 2016

Accepted Preprint published online 12 January 2016
() 2016 Society for Endocrinology Printed in Great Britain
Published by Bioscientifica Ltd. 